\title{
Public access defibrillation in Hong Kong in 2017
}

\author{
KL Fan, CT Lui, LP Leung *
}

\begin{abstract}
A B S T R A C T
The concept of public access defibrillation was proposed more than 20 years ago. Since then, various programmes have been implemented in many major cities although not all have been successful. Fourteen years ago, the question of whether Hong Kong needed public access defibrillation was raised. This article aimed to answer this question based on the best available evidence. Over the years, the clinical effectiveness of public access defibrillation in out-ofhospital cardiac arrest has been proven. Nonetheless various studies have indicated that among others, cost-effectiveness, knowledge and attitudes of the public, and incidence of ventricular fibrillation are important factors that will affect the likelihood of success of such programmes. In Hong Kong, because of the long interval between recognition of arrest and first defibrillation, public access defibrillation is probably needed. To ensure the success of such
\end{abstract}

a programme, careful planning in addition to the installation of more automated external defibrillators are essential.

Hong Kong Med J 2017;23:635-40

DOI: $10.12809 / \mathrm{hkmj} 176810$

${ }^{1}$ KL Fan, FHKAM (Emergency Medicine)

${ }^{2}$ CT Lui, FHKAM (Emergency Medicine)

${ }^{3}$ LP Leung *, FRCSEd, FHKAM (Emergency Medicine)

Accident and Emergency Department, The University of Hong KongShenzhen Hospital, Shenzhen, China

${ }^{2}$ Accident and Emergency Department, Tuen Mun Hospital, Tuen Mun, Hong Kong

Emergency Medicine Unit, Li Ka Shing Faculty of Medicine, The

University of Hong Kong, Pokfulam, Hong Kong

* Corresponding author: leunglp@hku.hk

\section{Introduction}

The prognosis of out-of-hospital cardiac arrest (OHCA) in Hong Kong is poor. Fewer than one in 44 persons with OHCA survive to hospital discharge. The number of survivors with good neurological outcome is even smaller (one in 67 persons with OHCA). ${ }^{1}$ Public access defibrillation (PAD) has been proposed as a strategy to improve survival. The concept was first put forward by the American Heart Association Task Force on Automatic External Defibrillation in $1995 .^{2}$ There is no strict definition of PAD but it is considered to include defibrillation by persons not medically trained. There were initially four levels of responders, ie persons performing the defibrillation before the arrival of the emergency medical services (EMS). Level 1 referred to the traditional first responders, eg police and firefighters. Level 2 were persons who had a duty of care, eg life guards and security personnel. Laypersons who had been trained in cardiopulmonary resuscitation (CPR) or use of an automated external defibrillator (AED) constituted the third level. Level 4 referred to minimally trained or untrained laypersons who may respond to an emergency.

Advances in technology have ensured the current AED is compact in size and easy to operate. Visual and auditory instructions allow a person without prior training to perform defibrillation. ${ }^{3}$ Fourteen years ago, a group of emergency physicians questioned whether PAD was needed in Hong Kong. ${ }^{4}$ In response to the culminating scientific evidence to support the use of PAD in OHCA, and the change in the environment and population demographics of Hong Kong over the past 14 years, this paper aimed to answer the same question again. A literature search was conducted using the electronic database of MEDLINE, Embase, and Scopus for primary clinical studies, as well as Cochrane Reviews and Health Technology Assessment and Database for secondary reviews, published from 1995 to the present. Keywords of cardiac arrest, survival, defibrillator, defibrillation, effectiveness, and AED were used singly or in combination. Additionally a manual search was performed of bibliographies listed in articles used for review. An article was included for review if all investigators agreed that it could provide data to answer the research question. It is hoped that the findings of this review will inform the health authorities and the government about community-based PAD programmes.

\section{Clinical effectiveness of automated external defibrillator}

Ventricular fibrillation (VF) is one of the causes of sudden OHCA. Defibrillation is the most effective treatment for patients with VF. The probability of successful defibrillation is time-dependent, dropping by $7 \%$ to $10 \%$ with each passing minute. ${ }^{5}$ 


\section{7年香港公共設施去顫計劃概況}

棎潔玲、雷俊達、梁令邦

自20多年前美國心藏協會提出公共設施去顫計劃概念以來，儘管並不 都是成功, 但計劃至今已涵蓋許多主要城市。14年前, 香港的醫護 人員也提出應否推行類似計劃。本文旨在以現有最佳證據為這問題提 供答案。多年來, 公共設施去顫計劃已被證實對院外心搏驟停具臨床 效果。然而, 各種研究顯示計劃的成本效益、公眾對計劃的認識和態 度, 以及心室顫動發生率均是影響公共設施去顫計劃會否成功的重要 因素。在香港, 由於確認心搏驟停與第一次去顫之間的長時間間隔, 公共設施去顫是有需要的。要使計劃取得成功, 除了安裝更多自動化 外部除顫器, 對計劃的審慎規劃也非常重要。
Defibrillation by a bystander with an AED prior to the arrival of EMS may shorten the time between arrest and defibrillation and thus increase the chance of survival. Early studies that compared CPR versus CPR plus AED by level 1 responders, ie police and firefighters, did not reveal any survival advantage of using an AED., ${ }^{6,7}$ In 2004, the PAD trial investigators published their report on PAD and survival after $\mathrm{OHCA}$ and presented the most convincing evidence of the clinical effectiveness of an AED. ${ }^{8}$ They randomised over 19000 volunteer responders from nearly 1000 communities in North America to an intervention group that used CPR and AED or a control group that used CPR alone. The intervention resulted in a 2 -fold increase in the chance of survival to hospital discharge. ${ }^{8}$ The failure to demonstrate any benefits of AED in the early studies may be related to the exclusion of the lay public in using AED. A metaanalysis that studied nearly 1600 cases of OHCA also demonstrated an increased probability of survival to hospital discharge if an AED was used for OHCA before EMS arrival (relative risk of 1.39 of surviving to hospital discharge for people treated with CPR + AED compared with CPR-only). ${ }^{9}$ In conclusion, there is concrete evidence that AED is clinically effective in OHCA.

\section{Cost-effectiveness of automated external defibrillator}

Before a PAD programme is implemented, policymakers need to consider many factors. Clinical effectiveness alone is not sufficient to justify the implementation of a PAD programme when there are competing demands for resources. An important question is how cost-effective of an AED is. Clinical effectiveness cannot be directly translated into cost-effectiveness. In fact, opinions about the cost-effectiveness of public placement of AEDs are divided. ${ }^{10,11}$

\section{Factors that affect cost-effectiveness}

In general, important factors that affect the costeffectiveness of public placement of AEDs include the incidence of OHCA at the placement site, the existing survival rate of OHCA in the community, and the number of AEDs required to provide adequate coverage. Different recommendations exist regarding the incidence of OHCA. The American Heart Association (AHA) recommends an AED be placed in sites where an OHCA can be expected every 5 years while the European Resuscitation Council recommends placing an AED in sites where an OHCA is expected every 2 years. ${ }^{12,13}$ If cardiac arrest at the placement site is rare, the AED is unlikely to be cost-effective. The survival to hospital discharge rate of OHCA in most regions is lower than $10 \%{ }^{14}$ The higher the survival rate, the lower the incremental benefit of adding an AED. It should also be noted that the survival rate is influenced by multiple factors and is not easily modifiable. A way to evaluate adequacy of coverage by an AED is to check whether a layperson can get an AED to the patient in 1 to 1.5 minutes. ${ }^{15}$ Based on the average speed of brisk walking, this can be translated into an AED being placed within 100 metres of a cardiac arrest. Nonetheless it is difficult to estimate the number of AEDs required even with perfect matching with the sites of possible arrest. This is because historical data used for matching cannot predict the future risk of an arrest at the same site. Therefore, the incidence of cardiac arrest at the placement site is probably a more significant factor to consider when the costeffectiveness of an AED is analysed. A number of studies have been conducted in the last decade on the cost-effectiveness of AED in public sites in terms of cost per quality-adjusted life year (QALY). Depending on the analytic model, maintenance and system support cost and the chance that the AED was used, in turn related to the incidence of cardiac arrests, the QALY ranged from US\$31000 to $\$ 198000 .^{16-18}$ Overall these studies concluded that sites where the incidence of cardiac arrests is more than once every 5 to 7 years will assume a more sustainable cost-benefit for AED placement. Examples include casinos, airports, and fitness centres. ${ }^{19}$

\section{It is more than clinical effectiveness and cost-effectiveness}

Presence of an AED does not mean that it will or can be used. The modern AED is easy to operate and skill retention by a lay rescuer is good. Data from the PAD trial indicate that it took 7 minutes only for retraining in AED operation more than a year after the initial training. ${ }^{20}$ Nonetheless completion of AED training does not guarantee that lay responders will use it when it is needed. In a Finnish study, the AED 
was available but not used in $65 \%$ of OHCAs. ${ }^{21} \mathrm{~A}$ similar figure was found in the PAD trial. ${ }^{8}$ There are likely multiple reasons for this high underutilisation rate. It may be that the responder is simply unaware of the presence of an AED or does not know its location. In addition, the public's willingness to use the AED may play a part. Fear of legal liability because a lack of Good Samaritan legislation is sometimes quoted as a reason for not providing help to the needy. ${ }^{22}$ Factors related to the AED itself may also be a concern. A survey on the functional status of public AEDs by Haskell et $\mathrm{al}^{23}$ identified problems such as battery expiry, inaccessibility, and invisibility of the AED. In other words, mere installation of AEDs is not enough to ensure success in a PAD programme. Proper organisation and maintenance of the AEDs must accompany any PAD programme.

Another important factor is the characteristics of the population at risk, eg age of patients with sudden cardiac death. The incidence of VF is lower in those older than 70 years than those below. ${ }^{24}$ The overall incidence of VF in OHCA has also fallen over the last two decades. ${ }^{25}$ This is believed to be a result of improved primary and secondary prevention of coronary heart disease as evidenced by the drop in the associated mortality in many parts of the world. ${ }^{26}$ Since defibrillation is only effective for OHCA with an initial rhythm of VF or pulseless ventricular tachycardia (VT), the need to implement PAD in regions, where the risk of VF is low, is less compelling.

\section{Whether public access defibrillation is needed in Hong Kong}

On the basis of the previous discussion, this question is to be addressed from two perspectives: the likelihood of PAD to improve survival of OHCA in Hong Kong, and factors that will affect the likelihood of successful implementation of a PAD programme.

\section{Likelihood of public access defibrillation to improve survival of out-of-hospital cardiac arrest}

The chain of survival is a widely accepted framework to improve OHCA survival. The chain is composed of early recognition with a call for EMS, early CPR, early defibrillation, effective advanced life support, and integrated post-arrest care. Almost all early local studies of OHCA highlighted the need to strengthen particularly the first three links in the chain. ${ }^{27-30}$ Of note, OHCA patients with VF in Hong Kong have a better prognosis than those with a non-shockable rhythm. ${ }^{31-33}$ The rate of survival to hospital discharge of patients with VF initially is 6 times that of patients with a non-VF rhythm. ${ }^{33}$ It is therefore not surprising to find that the time to first defibrillation is an independent predictor of OHCA survival in Hong Kong. ${ }^{1}$

Over the past 20 years, there has been a remarkable improvement in the time from arrest recognition to first defibrillation. The time interval was shortened by nearly 11 minutes from 23 minutes to 12 minutes. ${ }^{1,34} \mathrm{~A}$ possible important contribution to this improvement is the reduced recognitionto-activation interval from over 7 minutes to almost instantly. The reason for this reduction is unknown although wider use of mobile phones is a possibility. Whatever the reason, a time gap of at least 12 minutes between collapse and defibrillation is still far from desirable. The chance of successful defibrillation remains low. It is vital that means to reduce this time gap be found in order to increase the chance of successful defibrillation. Fourteen years ago, public education about OHCA, graded dispatch by ambulances, and a first responder (AED) programme by police or firefighters were discussed. ${ }^{4}$ No local studies have specifically addressed the issue of public education. On the contrary, there is evidence that the percentage of the public who have received $C P R$ training has increased over the last 10 years. ${ }^{35,36}$ Whether this increase in number of CPR-trained citizens can be translated to an increase in OHCA awareness is questionable. This is because even in the survey published in 2014, only $21 \%$ of the 1013 respondents had been trained; and overall, their CPR knowledge was poor. ${ }^{35}$ A graded dispatch system refers to one that prioritising the EMS response time is based on the urgency of calls. Similar to 14 years ago, there remains concern about affecting the overall service commitment by the Fire Services Department. It is unlikely that this practice will be adopted in the foreseeable future. With regard to the last suggestion to recruit police or firefighters as first responders, overseas experience has already shown that it is unlikely to improve OHCA survival. ${ }^{6,7}$ Based on the calculation of the investigators 14 years ago, employing this means could reduce the collapse to defibrillation interval by 4 minutes. Even with this optimistic assumption, the interval of 8 minutes remains long when applying the latest data. As a result, PAD by level 2 to 4 responders is probably needed to shorten the time to first defibrillation to 5 minutes or shorter, and hopefully improve the probability of OHCA survival.

\section{Factors affecting the likelihood of success of a public access defibrillation programme}

Public access defibrillation primarily involves public placement of AEDs to be used by non-medically trained members of the public in OHCA patients who present with a shockable rhythm. Factors that may affect the success of a PAD programme are multiple and those specific to Hong Kong are discussed below. 
Public placement of AEDs has to be preplanned. Evidence suggests that unguided AED placement is not effective in improving survival in $\mathrm{OHCA} .{ }^{37}$ In general, appropriate sites include locations where one can expect an OHCA every 5 years (AHA recommendation), EMS response time beyond 5 minutes, or facilities serving high-risk people. ${ }^{38}$ How the sites of AED placement are related to the cost-effectiveness of a PAD programme has also been discussed. In Hong Kong, because there is no compulsory AED registry, the location of all AEDs is unknown to the public. To make the best use of these AEDs, first of all, their location should be known by the public. The Government is in the best position to lead the development of an AED registry. Efforts to facilitate public knowledge of AED locations are also underway. For instance, a mobile phone application with an AED locating function is now available. ${ }^{39}$ Besides, the AED should be accessible by the public. A study of the accessibility and availability of 207 AEDs in 670 facilities in New Territories (NT) West published in 2014 provided some insight into this issue. ${ }^{40}$ The investigators found that many of the AEDs (37.7\%) were placed in schools in NT West. Whether these AEDs were truly accessible by the public was questionable as schools have limited opening hours. Nonetheless in Hong Kong, most OHCAs occur with the patient at home. Only $13.5 \%$ of cases occurred in public places or streets. ${ }^{1}$ Detailed planning of AED placement is thus essential to ensure that they are accessible and can be used by the public in an emergency. Regarding accessibility, Hong Kong may take reference from Japan and Singapore. In Japan, AEDs can be found in many vending machines on the streets and internetbased maps for AED location have been created in several cities. ${ }^{41}$ In 2015, Singapore launched a pilot programme that installed an AED in taxis with taxi drivers trained to use it. ${ }^{42}$

Since it is expected that an AED will be used by a layperson, public knowledge of and attitude to AED will influence the success of a PAD programme. According to a recently published survey, only $18 \%$ of respondents would use an AED in an OHCA and approximately $77 \%$ had no knowledge of the location of an AED near their home or workplace. ${ }^{22}$ These findings probably explain the very low rate of bystander defibrillation (1.4\%) in OHCA in Hong Kong. ${ }^{1}$ Simply increasing the number of AEDs installed without more extensive engagement of the public is bound to fail. Education, including recurrent training in AED use, by government or non-governmental organisations is indispensable in this aspect.

As defibrillation is only indicated for VF or pulseless VT, the incidence of these shockable rhythms in OHCA is an important consideration in a PAD programme. In Hong Kong, a fall in the incidence of VF in OHCA has been observed alongside a similar downward trend elsewhere. ${ }^{1,28}$ The latest study revealed an incidence rate of $8.7 \%{ }^{1}$ Whether the advanced age of the local OHCA patients is a contributing factor is unknown. It seems reasonable to postulate that like elsewhere, improved medical care of patients with coronary artery disease may be contributory. Nonetheless caution is needed in interpreting this incidence rate when PAD is considered. It is well known that patients with VF will soon become asystolic in the absence of any intervention. With a call to patient's side with an interval of 9 minutes by the EMS, it is possible that a proportion of VF cases will have already degenerated into asystole when the EMS connect them to the cardiac monitor. It has been estimated that about $53 \%$ of patients may be in VT or VF within 4 minutes of collapse from OHCA. ${ }^{43}$ If an effective PAD programme is in place, more VF cases will be identified by the AED machine.

\section{Conclusion}

Automated external defibrillator is clinically effective in improving the survival outcome of OHCA. Costeffectiveness is nonetheless dependent on multiple factors. In Hong Kong, there is a need to implement a PAD programme in order to shorten the time to first defibrillation, with itself being a predictor of survival. Based on the best available evidence for Hong Kong, strategic planning, eg matching the incidence of OHCA with AED placement, ensuring accessibility, and establishing an AED registry with an infrastructure of AED maintenance are recommended. Unguided placement of AEDs is discouraged because it is likely a waste of resources. In parallel, public engagement is essential. Both knowledge and attitude should be enhanced through education. Early defibrillation is just one of the links in the chain of survival. From the community perspective, basic life support by a bystander, eg CPR, deserves continued encouragement despite the increased bystander CPR rate to nearly $30 \%$ over the past 14 years. This is because high-quality bystander CPR may help prevent degeneration to asystole.

\section{Declaration}

All authors have disclosed no conflicts of interest.

\section{References}

1. Fan KL, Leung LP, Siu YC. Out-of-hospital cardiac arrest in Hong Kong: a territory-wide study. Hong Kong Med J 2017;23:48-53.

2. Weisfeldt ML, Kerber RE, McGoldrick RP, et al. Public access defibrillation. A statement for healthcare professionals from the American Heart Association Task Force on Automatic External Defibrillation. Circulation 1995;92:2763.

3. Eames P, Larsen PD, Galletly DC. Comparison of ease of 
use of three automated external defibrillators by untrained lay people. Resuscitation 2003;58:25-30.

4. Lo CB, Wong TW, Lai KK. Is public access defibrillation needed in Hong Kong? Hong Kong Med J 2003;9:113-8.

5. Valenzuela TD, Roe DJ, Cretin S, Spaite DW, Larsen MP. Estimating effectiveness of cardiac arrest interventions: a logistic regression survival model. Circulation 1997; $96: 3308-13$.

6. van Alem AP, Vrenken RH, de Vos R, Tijssen JG, Koster RW. Use of automated external defibrillator by first responders in out of hospital cardiac arrest: prospective controlled trial. BMJ 2003;327:1312.

7. Sayre MR, Evans J, White LJ, Brennan TD. Providing automated external defibrillators to urban police officers in addition to a fire department rapid defibrillation program is not effective. Resuscitation 2005;66:189-96.

8. Hallstrom AP, Ornato JP, Weisfeldt M, et al. Public-access defibrillation and survival after out-of-hospital cardiac arrest. N Engl J Med 2004;351:637-46.

9. Sanna T, La Torre G, de Waure C, et al. Cardiopulmonary resuscitation alone vs. cardiopulmonary resuscitation plus automated external defibrillator use by nonhealthcare professionals: a meta-analysis on 1583 cases of out-ofhospital cardiac arrest. Resuscitation 2008;76:226-32.

10. Gold LS, Eisenberg M. Cost-effectiveness of automated external defibrillators in public places: pro. Curr Opin Cardiol 2007;22:1-4.

11. Pell J, Walker A, Cobbe SM. Cost-effectiveness of automated external defibrillators in public places: con. Curr Opin Cardiol 2007;22:5-10.

12. Hazinski MF, Idris AH, Kerber RE, et al. Lay rescuer automated external defibrillator ("public access defibrillation") programs: lessons learned from an international multicenter trial: advisory statement from the American Heart Association Emergency Cardiovascular Committee; the Council on Cardiopulmonary, Perioperative, and Critical Care; and the Council on Clinical Cardiology. Circulation 2005;111:3336-40.

13. Handley AJ, Koster R, Monsieurs K, et al. European Resuscitation Council guidelines for resuscitation 2005. Section 2. Adult basic life support and use of automated external defibrillators. Resuscitation 2005;67 Suppl 1:S7-23.

14. Berdowski J, Berg RA, Tijssen JG, Koster RW. Global incidences of out-of-hospital cardiac arrest and survival rates: Systematic review of 67 prospective studies. Resuscitation 2010;81:1479-87.

15. Aufderheide T, Hazinski MF, Nichol G, et al. Community lay rescuer automated external defibrillation programs: key state legislative components and implementation strategies: a summary of a decade of experience for healthcare providers, policymakers, legislators, employers, and community leaders from the American Heart Association Emergency Cardiovascular Care Committee, Council on Clinical Cardiology, and Office of State Advocacy. Circulation 2006;113:1260-70.

16. Cram P, Vijan S, Fendrick AM. Cost-effectiveness of automated external defibrillator deployment in selected public locations. J Gen Intern Med 2003;18:745-54.

17. Nichol G, Huszti E, Birnbaum A, et al. Cost-effectiveness of lay responder defibrillation for out-of-hospital cardiac arrest. Ann Emerg Med 2009;54:226-35.e1-2.

18. Groeneveld PW, Owens DK. Cost-effectiveness of training unselected laypersons in cardiopulmonary resuscitation and defibrillation. Am J Med 2005;118:58-67.

19. Reed DB, Birnbaum A, Brown LH, et al. Location of cardiac arrests in the public access defibrillation trial. Prehosp Emerg Care 2006;10:61-76.

20. Riegel B, Birnbaum A, Aufderheide TP, et al. Predictors of cardiopulmonary resuscitation and automated external defibrillator skill retention. Am Heart J 2005;150:927-32.

21. Kuisma M, Castren M, Nurminen K. Public access defibrillation in Helsinki-costs and potential benefits from a community-based pilot study. Resuscitation 2003;56:14952.

22. Fan KL, Leung LP, Poon HT, Chiu HY, Liu HL, Tang WY. Public knowledge of how to use an automatic external defibrillator in out-of-hospital cardiac arrest in Hong Kong. Hong Kong Med J 2016;22:582-8.

23. Haskell SE, Post M, Cram P, Atkins DL. Community public access sites: compliance with American Heart Association recommendations. Resuscitation 2009;80:854-8.

24. Tresch DD, Thakur R, Hoffmann RG, Brooks HL. Comparison of outcome of resuscitation of out-of-hospital cardiac arrest in persons younger and older than 70 years of age. Am J Cardiol 1988;61:1120-2.

25. Bunch TJ, White RD. Trends in treated ventricular fibrillation in out-of-hospital cardiac arrest: ischemic compared to non-ischemic heart disease. Resuscitation 2005;67:51-4.

26. World Health Organization (WHO). Health for all database. Available from: http://www.euro.who.int/en/ data-and-evidence/databases. Accessed 1 Mar 2017.

27. Wong TW, Yeung KC. Out-of-hospital cardiac arrest: two and a half years experience of an accident and emergency department in Hong Kong. J Accid Emerg Med 1995;12:349.

28. Leung LP, Wong TW, Tong HK, Lo CB, Kan PG. Out-ofhospital cardiac arrest in Hong Kong. Prehosp Emerg Care 2001;5:308-11.

29. Wai AK, Cameron P, Cheung CK, Mak P, Rainer TH. Outof-hospital cardiac arrest in a teaching hospital in Hong Kong: descriptive study using the Utstein style. Hong Kong J Emerg Med 2005;12:148-55.

30. Lau CL, Lai JC, Hung CY, Kam CW. Outcome of out-ofhospital cardiac arrest in a regional hospital in Hong Kong. Hong Kong J Emerg Med 2005;12:224-7.

31. Leung KL, Lui CT, Cheung KH, Tsui KL, Tang YH. Outcome and prognostic factors of patients in out-ofhospital cardiac arrests presenting with non-shockable rhythm in Hong Kong. Hong Kong J Emerg Med 2012;19:612.

32. Chan TH, Lui CT, Cheung KH, Tang YH, Tsui KL. Outcome predictors of patients in out-of-hospital cardiac arrests with pre-hospital defibrillation in Hong Kong. Hong Kong J Emerg Med 2013;20:131-7.

33. Fan KL, Leung LP. Prognosis of patients with ventricular fibrillation in out-of-hospital cardiac arrest in Hong Kong: prospective study. Hong Kong Med J 2002;8:318-21.

34. Lui JC. Evaluation of the use of automatic external defibrillation in out-of-hospital cardiac arrest in Hong Kong. Resuscitation 1999;41:113-9.

35. Chair SY, Hung MS, Lui JC, Lee DT, Shiu IY, Choi KC. Public knowledge and attitudes towards cardiopulmonary resuscitation in Hong Kong: telephone survey. Hong Kong Med J 2014;20:126-33.

36. Cheung BM, Ho C, Kou KO, et al. Knowledge of 
cardiopulmonary resuscitation among the public in Hong Kong: telephone questionnaire survey. Hong Kong Med J 2003;9:323-8.

37. Ringh M, Herlitz J, Hollenberg J, Rosenqvist M, Svensson L. Out of hospital cardiac arrest outside home in Sweden, change in characteristics, outcome and availability for public access defibrillation. Scand J Trauma Resusc Emerg Med 2009;17:18

38. Atkins DL. Public access defibrillation: where does it work? Circulation 2009;120:461-3.

39. The University of Hong Kong. Technology Enhanced Learning Initiatives (TELI). Available from: http://teli.hku. hk/portfolio/aed-locator-app/. Accessed 1 Mar 2017.

40. Ho CL, Lui CT, Tsui KL, Kam CW. Investigation of availability and accessibility of community automated external defibrillators in a territory in Hong Kong. Hong Kong Med J 2014;20:371-8.

41. Mitamura H. Public access defibrillation: advances from Japan. Nat Clin Pract Cardiovasc Med 2008;5:690-2.

42. Singapore Civil Service College. SCDF's myResponder App helps saves lives. Available from: https://www.cscollege. gov.sg/Knowledge/Pages/SCDF-myResponder-AppHelps-Saves-Lives.aspx. Accessed 5 Jul 2017.

43. Herlitz J, Ekström L, Wennerblom B, Axelsson A, Bång A, Holmberg S. Type of arrhythmia at EMS arrival on scene in out-of-hospital cardiac arrest in relation to interval from collapse and whether a bystander initiated CPR. Am J Emerg Med 1996;14:119-23. 